\title{
The Influence of Leader Efficacy and Emotional Intelligence on Personal Caring in Physical Activity
}

\author{
T. Michelle Magyar, ${ }^{1}$ Marta R. Guivernau, ${ }^{2}$ \\ Lori A. Gano-Overway, ${ }^{3}$ Maria Newton, ${ }^{4}$ Mi-Sook Kim, ${ }^{5}$ \\ Doris L. Watson, ${ }^{6}$ Mary D. Fry ${ }^{7}$ \\ ${ }^{1} \mathrm{CSU}$ Long Beach, ${ }^{2}$ Michigan State University, ${ }^{3}$ Bridgewater College, \\ ${ }^{4}$ University of Utah, ${ }^{5}$ San Francisco State University, ${ }^{6}$ University of \\ Nevada, Las Vegas, ${ }^{7}$ University of Memphis
}

Key Words: sport, motivation, youth, leadership, coaching, pedagogy

Scholars in youth development, education, and sport are examining the formative contexts of classrooms, music halls, and playing fields to gain a better understanding of positive development in children. Of particular interest are the leaders in these contexts (e.g., teachers, conductors, and coaches) and their ability to nurture the social-emotional skills that provide the foundation for development across the lifespan (Elias, 2003; Kress, Norris, Schoenholz, Elias, \& Seigle, 2004).

Learning contexts that emphasize caring are fundamental to positive development because a caring and supportive environment positively influences children's social-emotional competencies, character development, and personal mastery (Elias, 2003; Kress et al., 2004; Noblit, 1993; Noblit, Rogers, \& McCadden, 1995; Noddings, 1995, 2002; Tappan, 1998; Wentzel, 1997). Student engagement in physical education is strengthened when students perceive their teachers as demonstrating a willingness to work with their students, showing a genuine concern for their well-being, and creating a safe and supportive environment that minimizes feelings of isolation (Cothran \& Ennis, 2000; Cothran, Hodges Kulinna, \& Garrahy, 2003; Larson, 2006). Specific to physical activity, Newton, Watson, et al. (in press) reported that children who perceived a strong caring environment in their youth sport camp setting expressed greater empathetic concern for their peers and expressed more interest in future camp participation. Yet as Noddings (1995, 2002) noted, caring is a relation and interaction that involves two perspectives, the perspective of the one feeling cared for and the perspective of the one providing the care.

Although the leader is essential in establishing a caring climate, there is limited research devoted to this important perspective. Noblit (1993) conducted an ethnographic investigation of one teacher's construction of caring through the ethical use of power or what he referred to as moral authority. Control in the classroom gave the teacher the opportunity to promote caring discipline through classroom rituals and clear communication regarding everyone's roles and responsibilities. Ethical 
exertion of power enabled the teacher to engage in reciprocal negotiation with students (who had less power and knowledge) to achieve a sense of consistency, security, and collective responsibility for learning and allowed the children to feel cared for (Noblit, 1993; Noddings, 2002).

Similar qualitative inquiries delineate teachers' rationale for engaging in caring behaviors in the physical education setting (Larson \& Silverman, 2005; Owens \& Ennis, 2005). This research demonstrates that a care ethic is deeply ingrained in their teaching philosophy primarily due to their personal history with physical education and exposure to caring role models. These teachers also described the importance of engaging in dialogue and establishing unique and meaningful relationships with their students that transcended the learning context. Even though this research provides important descriptive information regarding the physical education teacher's perspective of the caring relationship, additional research that examines individual differences in leader personal caring using a theoretical framework is warranted.

In the physical domain, Don Hellison's (1978, 1995, 2000, 2003) work provides pertinent information on the leader's perception of caring while teaching physical activity for at-risk youth. As part of his responsibility model, Hellison incorporates caring as a central component of his participant-centered physical activity program that focuses on the holistic development of the participants. He draws on the work of Noddings (1995) by stating that, "the focus is on truly caring, not just teaching kids about caring" (Hellison, 2000, p. 37). Buchanan (2001) examined physical activity leaders' experiences in implementing Hellison's $(1995,2000)$ model and found that most leaders viewed the model as useful but were unable to see past the levels of responsibility as a discipline and management program. As a result, little attention was given to individual development, growth, and caring for others. She discussed some of the contextual factors as problematic (i.e., limited time for training, actual implementation of the model) but noted the leaders' unwillingness or inability to relinquish control to the children in a manner that was necessary to empower them and teach them about self-responsibility.

These studies seem to suggest that developing a caring environment involves leaders being cognizant of opportunities to nurture caring relationships within the learning context and demonstrating a willingness to relinquish some control to the learners. One personal factor that may facilitate the development of a caring environment is leader efficacy, that is, confidence in one's ability to lead and teach others (Chase, Lirgg, \& Carson, 2001; Chemers, 2000). Researchers discuss the importance of considering efficacy in relation to caring because efficacious leaders are more likely to persist through adversity and because of this, efficacy is the characteristic that resonates most with the ethic of caring (Bandura, 1997; Chan, 2004; Goleman, Boyatzis, \& McKee, 2002; Knobloch, 2003; Murphy, 2002; Noddings, 1995, 2002). Efficacious teachers have been found to improve student behavior, learning, and management in the classroom (Chase et al., 2001). This is particularly important for teachers working with underserved youth because teachers who have an unwavering sense of confidence are more likely to have high expectations for their students and foster educational resilience in their classrooms (Knobloch, 2003; Wang, Haertel, \& Walberg, 1997). Furthermore, research demonstrates that as teachers become more confident in their teaching, they transition from concern for the self as disciplinarian in the classroom to concern for interpersonal relationships 
and creator of a caring environment for the children (Lundeen, 2004). Therefore, it is predicted that as leaders become more confident in their ability to teach, they could attend to the social-emotional development of their children.

In addition to leader efficacy, emotional intelligence, or an individual's ability to process and regulate emotional information (Goleman, 1995; Goleman, et al., 2002; Mayer \& Cobb, 2000; Mayer \& Salovey, 1997), may shed light on individual differences in the leader's ability to effectively teach in a caring manner. Leadership concerns the interaction of leaders with other individuals and, because interpersonal interactions are involved, emotional awareness and regulation are important factors that can influence the quality of these interactions. Research has found support for this proposition by linking emotional intelligence with effective leadership that is facilitated by the leader's ability to empathize, display optimism, and build morale (Caruso \& Wolfe, 2004; Goleman et al., 2002). These factors are related to caring and, therefore, we hypothesized emotional intelligence to serve as plausible influence on a leader's ability to care.

Given that the existing literature establishes a relationship between children's perceptions of a caring environment and subsequent positive developmental outcomes, it is practically and conceptually important to address pertinent characteristics within leaders that influence their ability to care. Therefore, the purpose of this study was to examine whether the leaders' efficacy and emotional intelligence would influence their ability to adequately care for their sport campers. Specifically, leader efficacy and emotional intelligence (i.e., self-emotional appraisal, appraisal of others' emotions, use of emotions, and regulation of emotions) were hypothesized to positively predict personal caring.

\section{Method}

\section{Participants}

Participants were 37 male $(n=16)$ and female $(n=21)$ group leaders from two summer NYSP sport camps for underserved youth. The group leaders reported an average of 4 years of experience with NYSP $\left(M_{\text {year }}=4.17, S D=6.5\right)$. The leaders represented a variety of racial-ethnic groups (46\% African American, $27 \%$ White American, 2.7\% Japanese, and 2.7\% Vietnamese; $21.6 \%$ did not identify their racial-ethnic group).

\section{Measures}

Personal Caring Scale. Leader perceptions of their ability to establish a caring climate were assessed using the Personal Caring Scale, a 14-item survey constructed for the purpose of this study. ${ }^{1}$ The Personal Caring Scale was designed to correspond with the Caring Climate Scale developed by Newton, Fry, et al. (in press) to assess youngsters' perceptions of the caring climate. This measure was based on the conceptual framework and literature on caring in youth educational contexts (Cohen, 2001; Noddings, 1995, 2002). Item development was particularly grounded in the work of Noddings's (1995) discussion of engrossment (being open-minded and responsive), motivational displacement (being more concerned for others than self), nonselectivity (treating children equally and confirming their 
ideas and values), and making youth a priority (explicitly stating that the children are important). On a 5-point Likert scale ranging from 1 (strongly disagree) to 5 (strongly agree), group leaders rated the extent to which they emphasize caring in their group environment (e.g., "I care about the kids."). Previous research has established the validity and reliability of the Caring Climate Scale (see Newton, Fry, et al., 2006). Personal caring scores were calculated for each leader by taking the average score of the 14 items.

Leader Efficacy. Leadership efficacy has been measured in the classroom (Woolfolk \& Hoy, 1990) and the physical education setting (Chase et al., 2001) in the form of teaching efficacy, in addition to the sport setting in the form of coaching efficacy (Feltz, Chase, \& Moritz, 1999). Distinct from the competitive sport environment, children participating in NYSP were introduced to novel sport skills (e.g., lacrosse, team handball, badminton) in a noncompetitive environment. As a consequence, leaders in this sport camp setting taught children movement and sport skills, making the instructional environment more similar to a physical education setting. Therefore, we expanded upon confidence in the notion to lead and specified that leadership efficacy in this context related to the confidence one had to successfully advance the learning of their campers.

Leader efficacy for implementing instruction was measured using a modified version of the Physical Education Teacher Efficacy Scale (M-PETES; Chase et al., 2001). This 16-item measure includes four subscales that asks leaders to rate their confidence in their ability to (a) motivate learners (e.g., "motivate your kids to persist after failing in skill attempts"), (b) analyze learner progress (e.g., "analyze what is wrong with a movement"), (c) prepare lesson plans (e.g., "prepare lessons that match the ability levels of your kids"), and (d) communicate effectively (e.g., "correctly explain technique cues for skills to your kids"). Leaders responded to the stem "How confident are you in your ability to . .." and scored each item on a 7-point rating scale ranging from 1 (no confidence at all) to 7 (extremely confident). Previous research establishes the validity and reliability of this measure (see Chase et al., 2001).

The measure was modified for the current investigation in the following ways: (a) we used the term leader efficacy instead of teaching efficacy, (b) we anchored the participants' responses specific to teaching situations in the NYSP camp setting, and (c) we changed certain words so that they were more appropriate given the current sample (e.g., "objective" was changed to "goal"). ${ }^{2}$ We were interested in the leaders' perceptions of their overall efficacy and therefore calculated the total efficacy score by taking the average for the 16 items.

Emotional Intelligence. A 16-item measure of emotional intelligence (Wong \& Law, 2002), which consisted of four subscales with 4 items per scale was used to examine leaders' (a) self-emotion appraisal (e.g., "I have a good understanding of my emotions"), (b) appraisal of others' emotions (e.g., "I am a good observer of others' emotions"), (c) use of emotions (e.g., "I am a self-motivated person"), and (d) regulation of emotions (e.g., " I am quite capable of controlling my own emotions"). Group leaders responded to each item on a 7-point Likert scale ranging from 1 (not at all true) to 7 (very true). Scores were created for each participant by calculating a mean score of all items for each scale. 


\section{Procedures}

Following approval from the university institutional review board, the NYSP leaders were asked to participate in the study. After providing consent for participation, all of the leaders completed a multisection questionnaire at the end of the 5-week camp. Leaders completed these measures in the privacy of a classroom setting. The questionnaire included a personal caring scale, a measure of emotional intelligence, and items tapping leader efficacy for implementing instruction, which took approximately $15 \mathrm{~min}$ to be completed.

\section{Analysis of Data}

Preceding statistical analysis, the raw data were inspected to ensure reliable data entry and testing of assumptions related to normality, linearity, and homogeneity. Basic statistics were calculated including internal reliabilities of measurements, means, standard deviations, and simple correlations among observed variables. The hypothesis was tested using multiple regression with self-emotion appraisal, other's emotion appraisal, use of emotion, regulation of emotion, and leader efficacy as the predictor variables and personal caring as the criterion variable. Owing to the exploratory nature of the study, there were no specific a priori hypotheses regarding the order of entry of the predictor variables and, thus, all independent variables were examined simultaneously. ${ }^{3}$

\section{Results}

\section{Descriptive Statistics}

Using Cronbach's alpha coefficient (Cronbach, 1951), all scales achieved acceptable levels of internal consistency (Table 1). Leaders seemed to appraise and regulate their own personal emotions and appraise the emotions of others in the NYSP environment, were confident in their ability to provide effective instruction, and perceived that they established a caring environment for the campers (Table 1).

\section{Table 1 Alpha Coefficients, Means, Standard Deviations, and Correlations for All Variables}

\begin{tabular}{|c|c|c|c|c|c|c|c|c|c|}
\hline \multirow{2}{*}{$\begin{array}{l}\text { Variables: } \\
\text { emotional intelligence, } \\
\text { leader efficacy, and } \\
\text { personal caring }\end{array}$} & \multirow[b]{2}{*}{$\alpha$} & \multirow[b]{2}{*}{$M$} & \multirow[b]{2}{*}{$S D$} & \multicolumn{6}{|c|}{ Simple correlations } \\
\hline & & & & 1 & 2 & 3 & 4 & 5 & 6 \\
\hline 1. Self-emotion appraisal & .80 & 6.02 & .81 & 1.00 & & & & & \\
\hline 2. Others' emotion appraisal & .77 & 5.86 & .89 & $.49 * *$ & 1.00 & & & & \\
\hline 3. Use of emotions & .83 & 6.02 & .87 & $.78 * * *$ & $.63 * * *$ & 1.00 & & & \\
\hline 4. Regulation of emotion & .92 & 5.57 & 1.20 & $.43^{*}$ & $.69 * * *$ & .42 & 1.00 & & \\
\hline 5. Leader efficacy & .96 & 5.63 & 1.08 & .34 & $.51 * *$ & $.61 * * *$ & .29 & 1.00 & \\
\hline 6. Caring & .94 & 4.40 & .57 & $.40^{*}$ & $.69 * * *$ & $.52 * *$ & $.65 * * *$ & $.57 * *$ & 1.00 \\
\hline
\end{tabular}

Note. Emotional intelligence and leader efficacy are assessed based on a 7-point Likert scale, and personal caring is based on a 5-point Likert scale.

$* p<0.05$ level, two-tailed, $* * p<0.01$ level, two-tailed, $* * * p<0.001$ level, two-tailed. 


\section{Predictive Utility of Emotional Intelligence and Leadership Efficacy}

Pearson product moment correlations revealed that the dependent variable, personal caring, was positively correlated with all of the independent variables (Table 1). ${ }^{4}$ Results of the multiple regression demonstrated that predictor variables were significantly associated with personal caring, $F(5,27)=7.98, p=.000, R^{2}=.60$, adjusted $R^{2}=.52$, accounting for $52 \%$ of the variance. More specifically, regulation of emotions and leader efficacy emerged as significant and positive predictors of personal caring (Table 2).

\section{Discussion}

The purpose of this study was to examine the influence of group leaders' efficacy and emotional intelligence on their perceptions that they care about their sport campers. All leaders reported that they were capable of assessing and regulating their personal emotions, and were attentive to the emotions of others in the camp setting. These leaders were also confident in their ability to motivate the summer campers, analyze the campers' progress on skill development, prepare for their camp lessons, and communicate effectively with the campers when teaching their respective sport skills.

Leadership efficacy emerged as a significant and positive determinant of personal caring. Researchers find that when leaders feel confident about their knowledge and their ability to advance the learning of their followers (e.g., students and employees) they are more likely to welcome and conquer adverse and difficult situations (Bandura, 1997; Chan, 2004; Chemers, 2000; Goleman et al., 2002; Knobloch, 2003). This is a particularly significant characteristic of leaders who want to work with underserved youth similar to the sample in the current investigation. Although Noddings's $(1995,2002)$ care theory is relation-centered, she addresses the elements of agency that are required to initiate and maintain an ethic of care. For example, Noddings states that when individuals are in the position of caring for others and decide that the capacity to care is important, they will find ways to increase this capacity, and that this process does not just happen, but rather there is a need to plan for it. Therefore, the leaders' deliberate and meaningful preparation is significant in their ability to create a caring environment.

Table 2 Multiple Regression Analysis for Emotional Intelligence and Leader Efficacy Predicting Personal Caring

\begin{tabular}{lccc}
\hline & \multicolumn{3}{c}{ Personal caring } \\
\cline { 2 - 4 } Predictor & $\boldsymbol{b}$ & $\alpha$ & $\boldsymbol{t}$ value \\
\hline Self-emotion appraisal & .005 & .01 & .03 \\
Others' emotion appraisal & .15 & .22 & 1.06 \\
Use of emotions & .01 & .02 & .06 \\
Regulation of emotion & .20 & .40 & $2.28^{*}$ \\
Leader efficacy & .19 & .33 & $2.01^{*}$ \\
$* p<0.05$ level, two-tailed. & & &
\end{tabular}


Emotional intelligence, as defined by the leaders' ability to assess and regulate their own personal emotions and understand the emotions of others, was also related in a significant and positive manner with personal caring. Thus, the current investigation is the first to introduce a meaningful relationship between the leaders' perceptions of their emotional skills with their perceived ability to care for their campers. The most influential emotional skill was the ability to regulate one's emotions (e.g., "I am able to control my temper and handle difficulties rationally"). This finding is notable because in order for leaders to establish caring relationships, they must be open, nonjudgmental, and fully receptive to the needs of their children, or what Noddings (1995) refers to as engrossment. Furthermore, she suggests that leaders engage in motivational displacement, or in essence, direct their energy and self-motivation toward the motivation of their children in an effort to really care about their interests. Thus, in order for leaders to effectively engage in caring, they must first utilize the affective or emotional regulatory skills that allow them to appraise and understand the emotional needs of their children.

\section{Conclusions and Future Directions}

To strengthen the examination of caring within the curricular themes of physical life and recreational life proposed by Noddings (2002), future researchers should consider adopting an integrative conceptual model similar to the one used in the current investigation that addresses both the agentic and relational properties of the caring context. This approach will further explain how caring relationships are initiated and sustained over long periods of time (e.g., academic year, sport season). Furthermore, because caring is embedded in everyday interactions, some researchers believe that in order to really see it and define it, one has to focus on the actual relationship and interaction between the one providing the care and the one receiving the care (Noblit, 1993; Tappan, 1998; Wentzel, 1997). To adequately address a limitation with the current investigation, future studies should adopt methodologies that allow for the simultaneous examination of these perspectives and behaviors. For example, rather than examine the children and leader data samples separately, one should consider the congruence between these perspectives using multilevel modeling and/or a qualitative examination (e.g., ethnographic, observation) that captures the discernible features that reflect the construction of the caring relationship.

Newton, Watson, et al. (in press) found that when children perceived a caring environment they reported greater empathetic concern and interest in future camp participation. Additionally, the current investigation indicated that leaders who were more confident in their ability to teach and who felt they were quite capable in assessing and regulating their own personal emotions and understanding the emotions of others were also more likely to perceive the climate they created to be caring. This preliminary research suggests that leaders (and subsequently, youngsters) have much to gain from enhancing their skills to potentially create a more caring environment.

In addition to the important theoretical contribution to the literature, the current findings also present some meaningful practical implications for program administrators, teachers, and coaches to consider. For example, physical activity 
programs can provide leaders with educational training (e.g., role playing) that enhances the skill set necessary for authentic caring. Specifically, administrators may prepare leaders so that they are more mindful of what occurs in the space between them and their children (i.e., consider what they are saying and how they say it, become more aware of their nonverbal communications with their children, and assess their energy levels to maintain an acceptable connection with their children). Furthermore, in order for authentic caring to take full effect, leaders must be presented with regular assessment and feedback that is both formal and informal. This practice will also enhance the self-regulatory strategies used by leaders that allow them to manage their own emotional self-regulation, thus, further enhancing their emotional confidence to deal with others.

Finally, the ethic of care should receive official acknowledgment at the programmatic level by being fully integrated into philosophy and policy statements. Two national standards for physical education teachers (NASPE, 2004) and youth sport coaches (NASPE, 2006) emphasize personal, social, and psychological development in students and athletes alike. Likewise, after-school and recreational programs should follow suit with these national standards and make caring an official part of the program philosophy and policy—only then will these programs adequately address the positive development of youth and adolescents.

\section{References}

Bandura, A. (1997). Self-efficacy: The exercise of control. New York: W.H. Freeman.

Buchanan, A.M. (2001). Contextual challenges to teaching responsibility in a sports camp. Journal of Teaching in Physical Education, 20, 155-171.

Caruso, D.R., \& Wolfe, C.J. (2004). Emotional intelligence and leadership development. In D.V. Day, S.J. Zaccaro, \& S.M. Halpin, (Eds.), Leader development for transforming organizations: Growing leaders for tomorrow (pp. 237-263). Mahwah, NJ: Erlbaum.

Chan, D.W. (2004). Perceived emotional intelligence and self-efficacy among Chinese secondary school teachers in Hong Kong. Personality \& Individual Differences, 36, 1781-1795.

Chase, M.A., Lirgg, C.D., \& Carson, R.L. (2001). Development of the Physical Education Teacher Efficacy Scale: Evaluation of Reliability, Concurrent and Construct Validity. Paper presented at the meeting of the American Association of Health, Physical Education, Recreation, and Dance Conference, Cincinnati, $\mathrm{OH}$.

Chemers, M.M. (2000). Leadership research and theory: A functional integration. Group Dynamics: Theory, Research, and Practice, 4, 27-43.

Cohen, J. (2001). Social emotional education. In Cohen, J. (Ed.), Caring classrooms/intelligent schools (pp. 3-29). New York, NY: Teachers College Press.

Cothran, D.J., \& Ennis, C.D. (2000). Building bridges to student engagement: Communicating respect and care for students in urban high schools. Journal of Research and Development in Education, 33, 106-117.

Cothran, D.J., Hodges Kulinna, R., \& Garrahy, D.A. (2003). "This is kind of giving a secret away..." students' perspectives on effective class management. Teaching and Teacher Education, 19, 435-444.

Cronbach, L.J. (1951). Coefficient alpha and the internal structure of tests. Psychometrika, $16,297-334$.

Elias, M.J. (2003). Academic and social-emotional learning. Educational Practice Series. International Bureau of Education, Geneva (Switzerland). International Academy of Education, Brussels (Belgium). Report: No-11.34p. 
Feltz, D.L., Chase, M.A., \& Moritz, S.E. (1999). A conceptual model of coaching efficacy: Preliminary investigation and instrumentation development. Journal of Educational Psychology, 91, 765-776.

Goleman, D. (1995). Emotional intelligence. New York: Bantam Books, Inc.

Goleman, D., Boyatzis, R., \& McKee, A. (2002). Primal leadership: Realizing the power of emotional intelligence. Boston, MA: Harvard Business School Press.

Hellison, D. (1978). Beyond bats and balls: Alienated (and other) youth in the gym. American Association of Health, Physical Education, Recreation, and Dance Conference, Washington, DC.

Hellison, D. (1995). Teaching responsibility through physical activity. Champaign, IL: Human Kinetics.

Hellison, D. (2000). Physical activity programs for underserved youth. Journal of Science and Medicine in Sport, 3, 238-242.

Hellison, D. (2003). Teaching responsibility through physical activity (2nd edition). Champaign, IL: Human Kinetics.

Kline, R.B. (1998). Principles and practice of structural equation modeling. New York: The Guilford Press.

Knobloch, N.A. (2003). College teachers "making a difference": A research review. North American Colleges and Teachers of Agriculture, 47, 47-53.

Kress, J.S., Norris, J.A., Schoenholz, D.A., Elias, M.J., \& Seigle, P. (2004). Bringing together educational standards and social emotional learning: Making the case for educators. American Journal of Education, 111, 68-89.

Larson, A. (2006). Student perception of caring teaching in physical education. Sport, Education, and Society, 11, 337-352.

Larson, A., \& Silverman, S.J. (2005). Rationales and practices used by caring physical education teachers. Sport, Education, and Society, 10, 175-193.

Lundeen, C.A. (2004). Teacher development: The struggle of beginning teachers in creating moral (caring) classroom environments. Early Child Development and Care, 174, 549-564.

Mayer, J.D., \& Cobb, C.D. (2000). Educational policy on emotional intelligence: Does it make sense? Educational Research, 12, 163-183.

Mayer, J.D., \& Salovey, P. (1997). What is emotional intelligence? In P. Salovey \& P. Sluyter (Eds.), Emotional development and emotional intelligence: Implications for educators (pp. 3-31). New York: Basic Books.

Murphy, S.E. (2002). Leader self-regulation: The role of self-efficacy and multiple intelligences. In R.E. Riggio \& S.E. Murphy (Eds.), Multiple intelligences and leadership (pp. 163-186). Mahwah, NJ: Erlbaum.

National Association for Sport and Physical Education (NASPE). (2004). Moving into the future: National standards for physical education (2nd ed.). Reston, VA: NASPE Publications.

National Association for Sport and Physical Education (NASPE). (2006). Quality coaches, quality sports: National standards for athletic coaches (2nd ed). Reston, VA: NASPE Publications. Designing quality programs. Reston, VA: NASPE Publications.

Newton, M., Fry, M., Watson, D., Gano-Overway, L., Kim, M., Magyar, M., \& Guivernau, M. (in press). Psychometric properties of the caring climate scale in a physical activity setting. Revista de Psicologia del Deporte.

Newton, M., Watson, D., Gano-Overway, L., Fry, M., Kim, M., \& Magyar, M. (in press). The role of a caring-based intervention in a physical activity. Urban Review.

Noblit, G.W. (1993). Power and caring. American Educational Research Journal, 30, 2338.

Noblit, G.W., \& Rogers, D.L., \& McCadden, B. (1995). In the meantime: The possibilities of caring. Phi Delta Kappan, 76, 680-685. 
Noddings, N. (1995). Teaching themes of care. Phi Delta Kappan, 76, 675-679.

Noddings, N. (2002). Educating moral people: A caring alternative to character education. New York, NY: Teachers College Press.

Owens, L., \& Ennis, C. (2005). The ethic of care in teaching: An overview of supportive literature. Quest, 57, 392-425.

Tabachnick, B.G., \& Fidell, L.S. (2001). Using multivariate statistics (4th ed.). New York: HarperCollins.

Tappan, M.B. (1998). Sociocultural psychology of caring pedagogy: Exploring Vygotsky's "Hidden Curriculum." Educational Psychologist, 33, 23-33.

Wang, M.C., Haertel, G.D., \& Walberg, H.J. (1997). Fostering educational resilience in inner-city schools. Children and Youth, 7, 119-140.

Wentzel, K.R. (1997). Student motivation in middle school: The role of perceived pedagogical caring. Journal of Educational Psychology, 89, 411-419.

Wong, C.S., \& Law, K.S. (2002). The effects of leader and follower emotional intelligence on performance and attitude: An exploratory study. The Leadership Quarterly, 13, 243-274.

Woolfolk, A., \& Hoy, W. (1990). Prospective teachers' sense of efficacy and beliefs about control. Journal of Educational Psychology, 82, 81-91.

\section{Notes}

1. Please contact the first author for detailed information on the psychometric properties of the Personal Caring Scale.

2. Please contact the first author for detailed information on the modifications made to the PETE.

3. The block single-step entry method was employed in the current investigation mainly because the stepwise method capitalizes on statistical chance that may "overfit" the data (e.g., Tabachnick \& Fidell, 2001). As a result, significant predictors that emerge in this sample may not emerge in different samples, making it difficult to interpret across different studies in the future.

4. The criteria established by Kline (1998) was used to determine whether there were any problematic issues with regard to bivariate and multivariate multicollinearity. Specifically, there is redundancy among the variables if the tolerance values ( 1 minus the squared multiple correlation between a variable and the rest of the variables) are less than $10 \%$ and the variance inflation factor (VIF; $1 / 1-R^{2}$ ) is greater than 10 . After running these analyses, we determined that the intercorrelation of .78 between self-emotion appraisal and use of emotions did not pose a problem to the overall regression analysis, and thus all four emotional intelligence variables were included in the analysis. 
Copyright of Journal of Teaching in Physical Education is the property of Human Kinetics Publishers. Inc. and its content may not be copied or emailed to multiple sites or posted to a listserv without the copyright holder's express written permission. However, users may print, download, or email articles for individual use. 